\title{
Future of enteral nutrition
}

\author{
D B A SILK \\ From the Department of Gastroenterology and Nutrition, Central Middlesex Hospital, London
}

SUMmaRY Although there has been agreement that enteral nutrition remains an excellent means of providing nutritional support to malnourished patients with normal or near normal gastrointestinal function, it is clear that areas of controversy do exist, and attention needs to be directed towards these in the future.

\section{Indications for nutritional support}

It is 10 years since Bristian et al published their papers showing that up to $50 \%$ of general medical and surgical inpatients showed some evidence of nutritional deficiencies. ${ }^{12}$ Their data had often been interpreted as implying that up to $50 \%$ of their patients were "malnourished" and therefore in need of nutritional support. Unfortunately, as time has moved on, it has become clear that it is difficult almost impossible - to agree on what actually represents clinically significant malnutrition. ${ }^{3}$ In practical terms what this means is that even if there is agreement that a patient is malnourished, it may not necessarily be clear that outcome will be affected on account of this, and therefore unclear as to whether nutritional support will be cost effective or of benefit to the patient.

It is perhaps hardly surprising that agreement on these points has not been reached, as it must be appreciated that in the inpatient malnutrition often arises as a consequence of the underlying disease process, and this may not be amenable to correction.

Research is therefore still required in the future to achieve a more perfect definition of malnutrition. Dionigi et $a l^{4}$ recently discussed the various anthropometric, biochemical, and immunological variables that have been used as indicators of protein energy malnutrition. As they ${ }^{4}$ and others have pointed out ${ }^{3}$ the relative value of each of these measurements has not been clearly defined, and the problems of arbitrarily setting normal limits, still persist.

If it is accepted that we are still unable to define what constitutes "clinically significant" malnutrition then it seems logical to continue to attempt dividing

Correspondence to: Dr D B A Silk. Department of Gastroenterology and Nutrition. Central Middlesex Hospital. I.ondon NW10 7NS. England. patients into high and low risk groups either on the basis of individual nutritional variables alone or by using various and complexly derived "weighting" systems. ${ }^{5-7}$ Although such studies enable one to predict with some certainty whether a patient is likely to be at risk of an increased morbidity or mortality, the question as to whether nutritional support affects morbidity or mortality in the "at risk" malnourished group still remains largely unanswered: most clinical trials of nutritional support have not been properly designed and have included normally nourished as well as malnourished patients. ${ }^{89}$

If clinical trials were to be designed sensibly - that is, identification of a high risk malnourished group, and these patients randomised to receive their normal nutritional intake alone or combined with nutritional support - then valuable information could be gained as to whether nutritional support can influence outcome, or whether the outcome is influenced by the underlying disease process. Using such means, the central question "is malnutrition clinically significant?" could be answered. One such trial has been performed recently by Bastow et al, ${ }^{10}$ who showed that malnutrition in elderly women with fractured femurs was likely to be clinically significant: patients randomised to receive supplementary nasogastric feeding had an appreciably quicker rehabilitation and earlier discharge from hospital than did the control malnourished patients.

\section{Practical aspects of enteral feeding}

DIET FORMULATION

Polymeric diets

Silk" reviewed the latest developments in the physiology of nutrient absorption, which apply to the formulation of enteral diets, and the indications for using polymeric, and the predigested "chemically 
defined elemental" diets have been discussed. With regard to the formulation of polymeric diets, issues for the future include the rationalisation of the carbohydrate energy source and the possible advantages of increasing the nitrogen and energy density of diets for routine clinical use from 1.0 to $1.5 \mathrm{kcal} / \mathrm{ml}$.

Jones et $\mathrm{l}^{12}$ have now clearly shown that purified starch hydrolysates containing glucose polymers of chain length 10 or more glucose molecules are satisfactorily assimilated in the normal human intestine, even in the absence of luminal $\alpha$ amylase activity. As the Table shows the osmotic contribution of the purified glucose polymers material is substantially less than the other carbohydrate energy sources tested, which are similar in composition to those used in most polymeric enteral feeds. Consideration could therefore be given to replacing the more heterogenous and relatively hyperosomolar carbohydrate energy sources with purified high new glucose polymer mixtures. ${ }^{11-1.3}$ This would have the effect of lowering diet osmolality and it would also be possible to increase the energy density of the present diets without changing osmolality by adding extra carbohydrate in the form of the purified high molecular weight glucose polymer mixtures.

One of the problems that has arisen in this unit during our experience of enteral feeding has been the inability to place all patients into positive nitrogen balance. ${ }^{14-16}$ There are many reasons for this, including the expected failure to overcome the hypermetabolic state of septic and severely traumatised patients, as well as the technical problems of administering enough feed. The technical problems identified include the poor performance of feeding tubes, ${ }^{17}$ use of starter regimens, ${ }^{16}$ the use of small volume containers, ${ }^{15}$ and the slowing of infusion rates due to the development of gastrointestinal side effects, particularly diarrhoea. ${ }^{18}$ I have also noted the

Table Osmolalities of carbohydrate substrates

Substrate $\left(100 \mathrm{~g} / \mathrm{Kg} \mathrm{H}_{2} \mathrm{O}\right)$

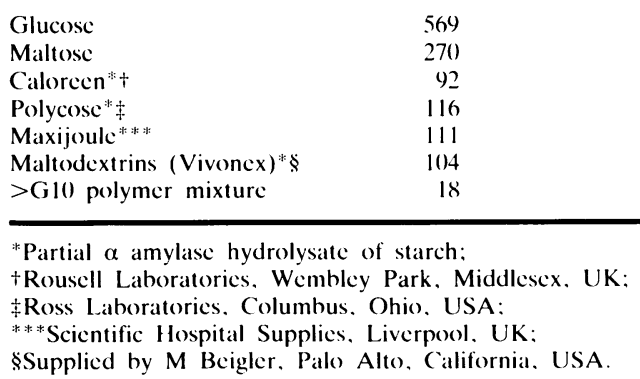

difficulties encountered by nursing staff in our general medical and surgical wards in administering more than $2 \cdot 0-2 \cdot 5$ litre enteral diet $/ 24$ hours. There could well be advantages to increasing the nitrogen and energy content of standard polymeric diets used for routine feeding, and we are currently testing a hypothesis that better nutrient balance can be obtained by feeding diets containing up to $9-10 \mathrm{~g}$ nitrogen $/ \mathrm{l}$ and $1.5 \mathrm{kcal} / \mathrm{ml}$ compared with the content of most of the standard diets currently available, which contain in the region of 5-6 g nitrogen $/ \mathrm{l}$ and $1.0 \mathrm{kcal} / \mathrm{ml}$. If the hypothesis is proved diet osmolality would increase, and again this could be lowered if the carbohydrate energy source was to be composed of higher molecular weight glucose polymer mixtures.

\section{Predigested chemically defined diets}

Results of basic physiological studies support a concept that oligopeptide mixtures rather than free amino acids should form the basis of the nitrogen source of these diets. ${ }^{11}$ As we have emphasised ${ }^{19}$ there is no evidence to support a nutritional superiority of peptides over free amino acids: two recent studies ${ }^{2}{ }_{21}$ purport to show that there is. In the first Smith et $\mathrm{al}^{2}$ showed consistently higher serum urea concentrations and higher urinary nitrogen excretion values in four patients fed with Vivonex HN (free amino acid nitrogen source) rather than Criticare $\mathrm{HN}$ (predominantly oligopeptide based nitrogen source). In the second Meguid et al, ${ }^{21}$ reported superior weight gains and increases in scrum albumin values in malnourished, stressed patients with head and neck cancer receiving Criticare HN instead of Vivonex HN. Although equicaloric and equinitrogenous feeding regimens were administered in both studies, neither group was able to circumvent the major flaw in study design - namely, that the amino acid patterns of the enteral diets administered were completely different. The two studies thus show that although Criticare$\mathrm{HN}$ is superior to Vivonex-HN, oligopeptides are not necessarily superior to free amino acids. To prove the superiority of a peptide based nitrogen source over an amino acid based nitrogen source, or otherwise, patients with severe impairment of gastrointestinal function must be randomised to receive equicaloric, isonitrogenous, predigested diets of similar and not different amino acid patterns.

One of my recent interests has centred on the assimilation of fluid and electrolytes during enteral feeding of patients with short bowel syndrome using predigested chemically defined diets. Concerned about the observation that patients with the short bowel syndrome, particularly those with extensive coexisting colonic resections, were getting diarrhoea 
when receiving predigested chemically defined diets, we started an intestinal perfusion study to investigate fluid and electrolyte absorption during infusion of an isotonic solution of the free amino acid based diet Vivonex HN. ${ }^{22}$ The results showed fluid and electrolyte secretion rather than absorption. Further experiments were undertaken in which a range of solutions containing the amino acid and glucose polymer components of Vivonex were perfused. Of a total of nine nutrient solutions studied, there was a linear correlation between initial sodium concentration and net sodium absorption, so that if the initial concentration exceeded $90 \mathrm{mmol} / \mathrm{l}$ net sodium absorption occurred, while at concentrations below this, sodium secretion was observed. Water absorption was linearly related to the net absorption of osmotically active particles, a substantial proportion of which was accounted for by the movement of sodium and its anions. It was therefore concluded that the net sodium secretion observed during perfusion of isotonic Vivonex is not a unique feature of this amino acid based diet but will occur during jejunal perfusion of any predigested diet with a low sodium content that does not contain sucrose as an added component of the glucose polymer based carbohydrate energy source.

Optimum absorption of water by the jejunal segment occurred with nutrient solutions containing $>90 \mathrm{mmol} / \mathrm{l}$ of sodium. ${ }^{22}$ The sodium content of Vivonex standard, Vivonex $H N$, Nutranel and Flexical, four currently available predigested chemically defined elemental diets, is $39 \cdot 2,36 \cdot 3$, $20 \cdot 1$ and $30 \cdot 1 \mathrm{mmol} / \mathrm{l}$, respectively, values that are substantially lower than would be required to promote net water absorption. On the basis of these findings, we feel that there are adequate experimental grounds for increasing the sodium content of predigested diets when it is planned to administer them to patients with the short bowel syndrome, particularly those who have coexisting colonic resections.

\section{TECHNIQUES OF ADMINISTRATION}

Jones $^{2.3}$ reviewed the current techniques used in administering enteral nutrition. While it is clear that considerable progress has been made during the past few years, we must continue to improve the design and performance of nasogastric feeding tubes and reach conclusions about the optimum size of diet reservoirs, as well as continuing research aimed at comparing the efficacy of pre-pyloric and postpyloric enteral feeding.

Feeding tube design and performance

As Bastow has pointed out ${ }^{2+}$ when wide bore tubes of the Ryle type are used for nasogastric feeding, the size and rigidity of the tubes tend to produce irritation and inflammation of the oesophagus with subsequent haemorrhage and stricture formation. In my experience such side effects are not seen with softer, narrower bore tubes. Nevertheless, the performance of the fine bore nasogastric feeding tubes is poor, with a non-elective removal rate of about $60 \% .{ }^{17}$ On the positive side it must be emphasised that although these tubes can be misplaced into the trachea during insertion, ${ }^{25}$ and perforation of the nasopharynx, ${ }^{26}$ oesophagus, ${ }^{27}$ and stomach ${ }^{28}$ has been described, these complications are rare. ${ }^{24}$ The high tendency of these tubes to dislodge is not reduced by using weighted tubes, ${ }^{17} \mathrm{a}$ fact that needs continuously emphasising to counteract the claims of the manufacturers. One further disadvantage of small internal diameter fine bore tubes, either the opened tip unweighted variety, or the weighted tubes with side vents, has been that their use makes aspirating stomach contents difficult. Changing the design of the exit port by ensuring that there are no slots, holes, ridges or right angles to trap solids or curdled feeds means that stomach contents can now be readily aspirated ( $\mathrm{R}$ Rees, D B A Silk, unpublished data). Unfortunately, as yet, there seems to be no easy answer as to how nasogastric tubes can be kept permanently positioned in the stomach.

\section{Nasogastric $v$ nasoenteral feeding}

The main disadvantage of nasoduodenal or nasojejunal feeding is that the pylorus is bypassed. Gastric emptying is mediated by the action of the pylorus, and the mechanisms underlying the "duodenal braking effect", whereby the rate of gastric emptying is governed by entry of gastric contents into the duodenum, have been analysed recently by Spiller. ${ }^{29}$ The importance of the duodenal brake is often ignored in enteral nutrition, and the point that needs emphasising for the future is that the osmotic load of nutrients presented to the duodenum does not depend on the product of diet osmolality and rate of diet infusion, but on the product of gastric effluent osmolality and rate of gastric emptying. The cramping, distension, and diarrhoea that occur during nasogastric feeding are probably related, at least in part, to the rapid secretion of fluid and electrolytes in response to the high osmotic load of nutrients entering the upper small bowel. The "duodenal brake" will reduce these symptoms if enteral feeds are infused intragastrically.

Although there have been no controlled clinical trials to support the theory, it does seem likely that regurgitation and aspiration of feed occur more commonly in nasogastrically than nasoenterally fed neurological patients. Particularly at risk are the 
aged, debilitated, demented and stuperous patients; those with poor gag reflexes and neuromotor deglutition disorders; and neurosurgical patients in the immediate postoperative phase.$^{30}$ This represents the subgroup of patients who should be fed nasoenterally. As far as possible and despite claims to the contrary, ${ }^{31}$ other patients should continue to be fed nasogastrically.

\section{Diet reservoirs}

Concern has been expressed over the possible role of nasogastric feeds as potential sources of infection and cross infection, especially in patients in intensive care units, ${ }^{32}$ and the whole subject of microbial contamination of enteral feeds has now been reconsidered. ${ }^{33}$

The concern about diet contamination led to the widespread use of $500 \mathrm{ml}$ diet containers that required changing at least every six hours. Bastow et $a l^{34}$ have shown that if sterile commercial feeds are carefully emptied into diet containers on the ward they remain sterile, whereas if a diet is blended with additives in the diet kitchen it is likely to become contaminated and subsequent bacterial multiplication occurs $\left(10^{8-10}\right.$ organisms $/ \mathrm{ml}$ after 24 hours' exposure to ward temperature $\left(21-24^{\circ} \mathrm{C}\right)$ ). As a consequence of this, it is clear that if enteral feeds are to be prepared in the diet kitchen then $500 \mathrm{ml}$ diet containers must be used. If pre-sterilised enteral diets are used without blending, then 1.5-2 litre containers can be used. Keohane et al ${ }^{15}$ have shown an added advantage of using large volume diet containers in that appreciably greater proportions of prescribed feed are actually administered from 1.5 and 21 containers relative to $500 \mathrm{ml}$ containers, with consequent benefits to the patient in respect of nitrogen balance. In my latest study I showed that although similar quantities of prescribed regimen were actually administered from 1 litre and 2 litre containers, pre-sterilised diet in prepackaged 2 litre containers was preferred by the nursing and dietetic staff who took longer to set up 1 litre containers as they had to be carefully filled on the ward with pre-sterilised diet poured from bottles or cans (R Rees, and D B A Silk, personal communication). I believe that the most efficient method of administering enteral feeds in countries where distribution is not a problem will be from prepackaged 2-3 litre reservoirs containing pre-sterilised, ready to infuse diet, and in countries where distribution is a problem, from $2-3$ litre reservoirs containing pre-sterilised, powdered diet to which sterilised distilled water is added on the ward.

DISEASE SPECIFIC FORMULATIONS

Enteral diets containing fibre

It is now inevitable that interest will focus on the use of diets containing fibre. The initial clinical interest in the early enteral diets stemmed from the experience of the American space exploration programme. The search for a diet that was, on the one hand, nutritionally complete and, on the other hand, would reduce stool output, led to the development of the first chemically defined predigested "elemental" diets. ${ }^{35}{ }^{36}$ Such diets, as well as the later polymeric diets, reduce stool weights as a consequence of containing small quantities of fibre. On the basis that the addition of $40 \mathrm{~g}$ of fibre/day to the polymeric diet ensure normalised stool weights and bowel function in normal male volunteers, ${ }^{37}$ the use of a diet containing fibre (Enrich, Abbott Laboratories Ltd, Queenborough, Kent) has been proposed in elderly and long term disabled patients, those requiring chronic tube feeding and home tube feeding, as well as those with constipation, and neurological patients with extended inactivity (Abbott Laboratories). Two litres of Enrich contains $42.2 \mathrm{~g}$ soya polysaccharide equivalent to $28.1 \mathrm{~g}$ dietary fibre, the same as a typical United Kingdom diet. ${ }^{38}{ }^{39}$ In a recent randomised cross over study, however, daily stool weights, bowel frequency, and incidence of gastrointestinal side effects in patients receiving 2 litre polymeric diet administered by continuous 24 hour nasogastric infusion were unaffected by the addition of $24 \mathrm{~g}$ carrot fibre. ${ }^{40)}$ The augmentation of enteral diets with fibre increases their viscosity and may make the diets more difficult to administer through narrow bore feeding tubes. On the basis of this recent clinical research in enterally fed patients, ${ }^{41}$ there seems to be no rationale to prescribing enteral diets containing the present quantities of fibre. It is hoped that in the future clinicians will bear in mind the cost factor of adding fibre to enteral feeds before being persuaded to prescribe them.

\section{Respiratory and cardiac failure}

In an important study respiratory, cardiovascular, and metabolic changes were monitored during balance studies in undernourished patients receiving continuous enteral feeding. ${ }^{41}$ With increasing energy infusion rates oxygen consumption, carbon dioxide production, minute ventilation, heat production, heat release, and heart rate increased on both a high carbohydrate and high fat diet. Rather disturbingly, increases in carbon dioxide production and minute ventilation were greater for the high carbohydrate relative to the high fat formula. In the clinical setting care must be taken not to precipitate heart failure during continuous enteral feeding in compromised patients. Furthermore, these findings also suggest that the ratio of carbohydrate to fat should be decreased in enteral 
diets administered to patients with respiratory failure. A new diet (Pulmocare, Ross) has been formulated along these lines. There will clearly be a need for more research to be undertaken in this important area.

\section{BRANCHED CHAIN ENRICHED ENTERAL DIETS Stress}

There has been much interest in the role of branched chain amino acids (BCCA) in the management of the stressed patient. The plasma concentrations and catabolism of the BCAAs change under stress $^{42}$ and as in vitro incubations of isolated muscle indicate that leucine specifically increases the rate of protein synthesis and decreases the rate of protein degradation, ${ }^{4-47}$ a special role for BCAAs as anticatabolic amino acids in stressed patients has been proposed.

It can be argued, however, that the in vitro studies were grossly unphysiological as all preparations were in negative nitrogen balance (degradation $>$ synthesis). In vivo leucine has no effect on muscle protein synthesis, even at greatly increased concentrations, ${ }^{48}$ and it is thus hard to justify the use of BCAA enriched formulations in enteral nutrition. Although Cerra et $a l^{49}$ showed that enriched parenteral solutions seemed to give a more rapid return to a positive nitrogen balance than standard solutions after abdominal surgery, the cumulative nitrogen balances measured over six days were the same. In their most recent study ${ }^{50} \mathrm{BCAA}$ enriched enteral diets resulted in better nitrogen balance after five and seven days' feeding than standard diets in "moderately high ICU stress" $(>10$ g urinary nitrogen/day). Any potential clinical benefits were not reported. The remaining controlled trials published recently were disappointing. Of the seven studies, one has shown greater nitrogen loss with high $\mathrm{BCAAs}^{51}$ and six have shown no difference in protein metabolism and nitrogen balance. ${ }^{52-57}$

The current vogue for using BCAA enriched formulations for stressed or catabolic patients is therefore probably misconceived for two reasons. Firstly, the metabolic rationale for high concentrations of BCAAs and a specific role for leucine are questionable. Secondly, there has been no convincing proof over the past few years of a definite clinical benefit from these solutions.

\section{Hepatic encephalopathy}

The use of enteral or parenteral formulation containing BCAAs, alone or in combination with other essential and non-essential amino acids in the management of malnourished cirrhotic patients with encephalopathy, remains topical and certainly controversial. 58
INFLAMMATORY BOWEL DISEASE

Although it would be an oversimplification to conclude that a specially formulated enteral diet is required in inflammatory bowel disease, the free amino acid based diet Vivonex HN seemed to have a considerable primary therapeutic effect in achieving a remission in patients with acute Crohn's disease. ${ }^{21}$ It remains to be established as to whether the symptoms of Crohn's disease were alleviated purely as a consequence of nutritional support per se, or whether the diet changed the bacterial flora in a beneficial way, or, indeed, whether the benefits were related to the hypoallergic properties of the free amino acid nitrogen source of the diet. Further research is needed to answer these questions. At the time of writing Vivonex is the only enteral feed that has been shown under controlled clinical trial conditions to have a specific primary therapeutic effect in patients with Crohn's disease.

\section{Conclusion}

This review has concentrated on the areas in the field of enteral nutrition that are associated with some uncertainty or controversy. The future of enteral nutrition is, however, assured. In my experience some three quarters of all patients requiring nutritional support can be fed via the enteral route. The indications for starting enteral feeding need continuous reappraisal. There is still scope for rationalising the formulation of the standard polymeric and predigested diets, and we need to strive to improve techniques for administering them. Finally, we should continue to assess critically the results of studies that are quoted by manufacturers as purporting to show appreciable clinical benefits for any of the new enteral diets formulated to satisfy the metabolic demands of specific underlying disease states.

\section{References}

1 Bristian BR, Blackburn GL, Hallowell E, Heddle R. Protein status of general surgical patients. JAMA 1974; 230: $858-60$.

2 Bristian BR, Blackburn GL, Vitale J, et al. Prevalence of malnutrition in general medical patients. JAMA 1976; 235: 1567-70.

3 Sutton G, Karran SJ. The diagnosis of malnutrition: nutritional parameters. Current Opinion in Gastroenterology 1985; 1: 281-7.

4 Dionigi R, Dominioni L, Jemos V, et al. Diagnosing malnutrition. Gut 1986; 27 (suppl): 5-8.

5 Buzby GP, Mullen JL, Matthews DC, et al. Prognostic nutritional index in gastrointestinal surgery. Am J Surg 1979; 139: 160-7.

6 Baker JP, Detsky AS, Whitwell J, Langer B, Jeejebhoy $\mathrm{KN}$. A comparison of the predictive value of nutritional 
assessment techniques. Hum Nutr Clin Nutr 1982; 36: 233-41.

7 Klidjian AM, Archer TJ, Foster KJ, et al. Detection of dangerous malnutrition. JPEN 1982; 6: 119-23.

8 Silk DBA. Nutritional support in hospital practice. Oxford: Blackwell Scientific Publications, 1983: 27-41.

9 Koretz RL. What supports nutritional support? Dig Dis Sci 1984; 29: 577-88.

10 Bastow MD, Rawlings J, Allison SP. Benefits of supplementary tube feeding after fractured neck of femur: a randomised controlled trial. Br Med J 1983; 287: 1589-92.

11 Silk DBA. Diet formulations and choice of enteral diet. Gut 1986; 27 (suppl): 40-6.

12 Jones BJM, Brown BE, Grimble GK. Silk DBA. The formulation of energy dense enteral feeds - the use of high molecular weight glucose polymers. JPEN 1981; 5: 359.

13 Jones BJM. Glucose polymer absorption from the human jejunum. London: University of London, 1984. (Thesis.)

14 Jones BJM, Lees R, Andrews J, et al. Comparison of an elemental and polymeric enteral diet in patients with normal gastrointestinal function. Gut $1983 ; 24$ : 78-84.

15 Keohane PP, Attrill H, Love M, Frost P, Silk DBA. A controlled trial of aseptic enteral diet preparation significant effects on bacterial contamination and nitrogen balance. Clin Nutr 1983; 2: 119-22.

16 Keohane PP, Atrill $\mathrm{H}$, Love $\mathrm{M}$, et al. Relations between osmolality of diet and gastrointestinal side effects in enteral nutrition. $\mathrm{Br}$ Med $J$ 1984: 288: 678-81.

17 Keohane PP, Atrill H, Jones BJM, Silk DBA. Limitations and drawbacks of 'fine bore' nasogastric feeding tubes. Clin Nutr 1983; 2: 85-6.

18 Jones BJM, Payne S, Silk DBA. Indications for pump assisted enteral feeding. Lancet 1980; i: 1057-9.

19 Keohane PP, Silk DBA. Peptides and free amino acids. In: Robeau JL, Caldwell MD, eds. Enteral and tube feeding. Philadelphia: W B Saunders Co, 1984: 44-59.

20 Smith JL, Arteaga C, Heymsfield SB. Increased ureagenesis and impaired nitrogen use during infusion of a synthetic amino acid formula, a controlled trial. $N$ Engl J Med 1982; 306: 1013-18.

21 Meguid MM, Landel AM, Terz JJ, Akrabawi SS. Effect of elemental diet on albumin and urea synthesis: comparison with partially hydrolysed protein diet. J Surg Res 1984; 37: 16-24.

22 Spiller RC, Brown B, Silk DBA. Sodium and water fluxes during jejunal perfusion of isotonic elemental and polymeric diets in man. Gastroenterology 1982; 5: 1186.

23 Jones BJM. Enteral feeding: techniques and administration. Gut 1986; 27 (suppl): 47-50.

24 Bastow MD. Complications of enteral nutrition. Gut 1986; 27 (suppl): 51-5.

25 Sweatman AJ, Tomasello PA, Houghhead MG, et al. Misplacement of nasogastric tubes and oesophageal monitoring devices. Br J Anaesth 1978; 50: 389-392.

26 Siemers PT, Reinke RT. Perforation of the nasopharynx by nasogastric intubation: a rare cause of left pleural effusion and pneumomediastinum. Am J Radiol 1976; 127: 341 .
27 James RH. An unusual complication of passing a narrow-bore nasogastric tube. Anaesthesia 1978; 33: 716.

28 Ghahremani GG, Turner MA, Port RB. Iatrogenic intubation injuries to the upper gastrointestinal tract in adults. Gastrointest Radiol 1980; 5: 1-10.

29 Spiller RC. The influence of fat on human small bowel motility. Cambridge: University of Cambridge. 1985. (Thesis.)

30 Olivares L, Segoria A, Refuella A. Tube feeding and lettal aspiration in neurological patients: a review of 720 autopsy cases. Stroke 1974; 5: 654-7.

31 Kiver KF, Hayes DP, Fortin DF, Maini BS. Pre and post-pyloric enteral feeding: analysis of safety and complications. JPEN 1984; 8: 95.

32 Casewell MW. Nasogastric feeds as a source of Klebsiella infection for intensive care patients. Research and Clinical Forums 1979; 1: 101-6.

33 Anderton A. Microbiological aspects of the preparation and administration of naso-gastric and naso-enteric tube feeds in hospitals - A review. Hum Nutr Appl Nutr 1983; 37A: 426-40.

34 Bastow MD, Greaves P, Allison SP. Microbial contamination of enteral feeds. Hum Nutr Appl Nutr 1982; 36A: 213-17.

35 Greentein JP, Otey MC, Birnbaum S, et al. Quantitative nutritional studies with water soluble, chemically defined diets. X. Formulation of a nutritionally complete diet. JNCI 1960; 24: 211-19.

36 Winitz M, Seedman DA, Graff J. Studies in metabolic nutrition employing chemically defined diets. I. Extended feeding of normal human adult males. Am J Clin Nutr 1970; 23: 211-19.

37 Bowen PE, McCallister M, Thye FW, et al. Bowel function and macronutrient absorption using fibreaugmented liquid formula diets. JPEN 1982; 6: 588 .

38 Southgate DAT. Dietary fibre: analysis and food sources. Am J Clin Nutr 1978; 31: 107-10.

39 Johnson CK, Kolasa K, Chenoweth W, et al. Health, laxation, and food habit influences on fibre intake of older women. J Am Diet Assoc 1980); 77: 551-7.

40) Patil DH, Grimble GK, Keohane PP, et al. Do fibre containing enteral diets have advantages over existing low residue diets? Clin Nutr 1985; 4: 67-72.

41 Heymsfield SB, Head A, McManus CB, Seitz S. Staton GW, Grossman GD. Respiratory, cardiovascular and metabolic effects on enteral hyperalimentation: influence of formula dose and composition. Am J Clin Nutr 1984; 40: 116-30.

42 Walser M. Therapeutic aspects of branched-chain amino and keto acids. Clin Sci 1984; 66: 1-15.

43 Buse MG, Jursinic S, Reid SS. Regulation of branched chain amino acid oxidation in isolated muscle nerves and aortas of rats. Biochem $J$ 1975; 148: 363-74.

44 Buse MG, Reid SS. Leucine, a possible regulator of protein turnover in muscle. J Clin Invest 1975; 56: 1250-61.

45 Fulks RM, Li JB, Goldberg AL. Effects of insulin, glucose, and amino acids on protein turnover in rat diaphragm. J Biol Chem 1975; 250: 290)-8.

$46 \mathrm{Li} \mathrm{JB}$. Jefferson LS. Influence of amino acid avail- 
ability on protein turnover in perfused skeletal muscle. Biochem Biophys Acta 1978; 544: 351-9.

47 Lundholm K, Edstrom S, Ekman L, et al. Protein degradation in human skeletal muscle tissue: the effect of insulin, leucine, amino acids and ions. Clin Sci 1981; 60: $316-19$.

48 McNurlan MA, Fern EB, Garlick PJ. Failure of leucine to stimulate protein synthesis in vivo. Biochem J 1982; 204: 831-8.

49 Cerra FB, Upson D, Angelico R, et al. Branched chains support postoperative protein synthesis. Surgery 1982; 92: 192-8.

50) Cerra FB, Shronts EP, Konstantinides NN, et al. Enteral modified amino acids (MAA) are efficacious in ICU stress. JPEN 1985; 9: 108.

51 Lenssen P. Cheney C, Aker S, et al. High branched chain amino acid trial in marrow transplantation for leukemia. JPEN 1985; 9: 124.

52 Kirvela O, Takala J. The effect of branched chain amino acids and the keto-analogues on postoperative $\mathrm{N}$ balance and liver protein synthesis. Clin Nutr 1985; 4 (suppl): 70 .
53 De Jong KP, von Meyenfeldt MF, Rouflart M, et al. The effect of branched chain amino acids (BCAA) on organ functioning in septic and stressed patients. Clin Nutr 1985; 4 (suppl): 71.

54 Gelin M, van de Stadt J, Lambillotte JP, Wybran J. Humoral and cellular immunological response to standard and BCAA enriched solutions of TPN. Clin Nutr 1985; 4 (suppl): 72.

55 Nuutinen L, Wistbaka J-O, Kaukinen S, et al. The comparison of 'normal', BCAA-enriched and intracellular amino acid change adapted amino solutions used after major abdominal surgery. Clin Nutr 1985; 4 (suppl): 73.

56 Pessi T, Koivula T, Kaukinen S, Marnela KM. Significance of branched chain amino acids in parenteral nutrition of patients with severe acute haemorrhagic pancreatitis. Clin Nutr 1985; 4 (suppl): 74.

57 Bonau RA, Daly JM, Moldawer L, Blackburn G. Muscle amino acid flux in patients receiving BCAA solutions. JPEN 1985; 9: 66.

58 Silk DBA. Branched chain amino acids in liver disease: fact of fantasy? Gut 1986; 27 (suppl): 103-10. 